\section{Renacimiento, Manierismo, Barroco}

Ana Cravino *

Resumen: El diseño de interiores del Renacimiento, Manierismo y Barroco se caracterizó por empleo de formas estilísticas de la antigüedad greco-romana y por la utilización de un sistema ordenado de proporciones geométricas. La espacialidad así configurada fue evolucionando de propuestas simplificadas y definidas a soluciones de gran complejidad y ambigüedad.

Palabras claves: Alberti - Barroco - Borromini - Bramante - Brunelleschi - Capilla Pazzi - Diseño de interiores - Il Redentore - Manierismo - Palladio - Renacimiento - San Pedro in Montorio - Sant'Andrea Mantua - Sant'Ivo.

[Resúmenes en inglés y portugués en la página 105]

(*) Arquitecta (UM); Profesora Superior Universitaria (UM); Magíster en Gestión de Proyectos Educativos (CAECE); Doctoranda (FADU-UBA) Docente e Investigadora, Universidad de Buenos Aires, Morón e ITBA.

\title{
Introducción
}

Este trabajo, orientado a reflexionar sobre la calidad de los espacios interiores en el Renacimiento, Manierismo y Barroco, se centrará en el territorio de Italia por considerar la producción de este país paradigmática, no sólo por ser impulsor de esta corriente de 'renacimiento' de las artes clásicas, sino por encontrarse allí obras en el estado más puro de cada una de las etapas que transita este movimiento estilístico. Siguiendo a Gombrich (1987, p. 322), se hablará de 'Renacimiento', 'Manierismo' y 'Barroco', y, también, se tomarán estas tres etapas como una unidad.

Serán analizados para este fin los siguientes ejemplos: La Capilla Pazzi de Filippo Brunelleschi (1441); Sant'Andrea Mantua de León Batista Alberti (1470); San Pedro in Montorio de Donato Bramante (1502-1510); Il Redentore de Andrea Palladio (1577) y Sant'Ivo de Francesco Borromini (1642-1660).

Coincidiendo con Norberg Schulz (1980,p. 231) se puede señalar que fueron dos las características de este lenguaje: por un lado, la geometrización, obtenida mediante el empleo riguroso de relaciones matemáticas y formas geométricas elementales; por el otro, la antropomorfización, consecuencia de la filosofía humanista, alcanzada por la reintroducción del repertorio estilístico de la antigüedad clásica. En relación a la primera característica, Wittkower (1979) señalaba que 
los artistas del renacimiento adherían firmemente a las tesis pitagóricas, pues todo era número, coincidiendo al respecto Benévolo (1981, p. 102) al analizar la capilla Pazzi, pues afirma que: "No sólo el organismo obedecía a una rigurosa construcción geométrica, sino que las medidas fundamentales corresponden a números enteros".

\section{Relación interior-exterior}

Es interesante notar en este período de más de 200 años, una evolución en la relación entre el interior y el exterior fundamentada en la búsqueda de consistencia formal entre ambos aspectos, que en una primera fase - por ejemplo, Catedral de Florencia, Iglesia de San Lorenzo, incluso Santa María Novella - podían ser tratados de manera prácticamente independiente. No obstante vale aclarar que la composición de las fachadas no responde en modo alguno a la lógica de la estructura soporte del edificio, sino que es una ornamentación añadida, como lo demuestran algunas obras inconclusas - Santa María delle Carceri de Sangallo, San Lorenzo de Brunelleschi. Asimismo, es de destacar que, como señala Bruno Zevi (1980, p. 84): "Todo el esfuerzo del Renacimiento consiste en acentuar el control intelectual del hombre sobre el espacio arquitectónico ...”; lo que en la concepción de Zevi incluiría substancialmente el espacio interior. Es por ello que esta relación exterior-interior aparece distorsionada en función de objetivos racionales. Por consiguiente, las variaciones topográficas del terreno, así como las características del entorno natural o urbano no serán tenidas en cuenta como condicionantes del proyecto, sino por el contrario será el proyecto quien modifique su entorno. Señala Norberg Schulz (1980, p. 226) respecto a la pretensión de autosuficiencia del hombre renacentista y al estudio de tipos ideales que “... la iglesia podía haber sido erigida en cualquier lugar ...."

La Capilla Pazzi, por ejemplo, se encuentra ubicada en los jardines de la basílica medieval de Santa Croce de Florencia, accediendo a través del claustro de la misma. Su fachada es un pórtico de cinco tramos formado por seis columnas de orden compuesto, mientras que en el tramo central adopta una forma de arco de triunfo, los otros cuatro están adintelados - Heydenreich (1991, p. 26) plantea ciertas dudas sobre la autoría del pórtico pues se supone posterior a Brunelleschi -. Este atrio, que actúa como espacio de transición entre el adentro y el afuera, se encuentra cubierto por dos bóvedas de cañón y una cúpula central. El interior es un objeto en sí mismo, que como el exterior, permite contemplar la lógica geométrica del Renacimiento. Dentro del pórtico aparece una nueva fachada conformada por una gran puerta en el centro remarcada por un frontón triangular con un par de ventanas a cada lado. En eje con la entrada se encuentra, en un luneto, un pequeño altar que también tiene una ventana vertical y otra circular en su parte superior. Tanto el vitreaux de la pared trasera como las ventanas del frente, así como la linterna y las pequeñas ventanas que enmarcan la cúpula central, posibilitan la entrada de la luz, pero nada muestran del exterior. 


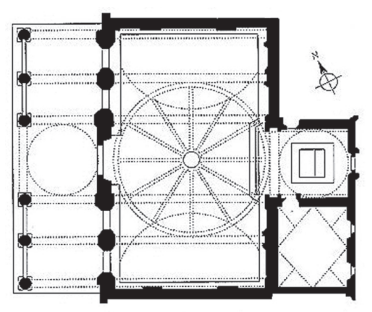

Figura 10. Capilla Pazzi (claustro de la Iglesia de Santa Croce), Florencia, planta.

Fuente: Reproducción de Roberto Céspedes.

Una situación similar se presenta en la Iglesia Sant'Andrea de Mantua, situada frente a la Piazza Mantenga - la cual permite una excepcional perspectiva de la fachada -. En ésta se conjuga la tipología romana del arco de triunfo con del templo griego, adoptando Alberti, asimismo, un gigantesco orden de pilastras que se alzan para soportar un frontón triangular. Para Summerson (1996, p.32) “... toda la iglesia, por dentro y por fuera, era como la ampliación lógica a tres dimensiones del arco de triunfo ..... El espacio central del pórtico es el doble de ancho que el de los laterales, siendo que unos y otros están cubiertos por bóvedas de cañón. La altura mayor del espacio central ofrece un profundo atrio cubierto por una estructura casetonada que enfatiza la simetría del conjunto. Las ventanas en el interior permiten el acceso de luz de manera casi dramática, pero con escasa visibilidad del exterior.

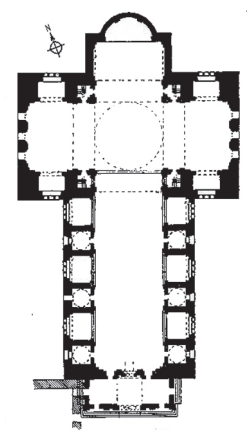

Figura 11. Iglesia de Sant'Andrea, Mantua, planta.

Fuente: Reproducción de Roberto Céspedes.

El mismo Alberti (1991, p. 311) señalaba que

Las ventanas de los templos deben ser de diversas medidas y estar muy elevadas, con el fin de que a través de ellas no puedas ver más que el cielo, y de que ni los oficiantes ni los fieles aparten sus mentes lo más mínimo de la divinidad. 
San Pedro in Montorio es un ejemplo similar al de la capilla Pazzi ya que también se encuentra ubicado en el interior de un patio, en este caso, el del convento franciscano de Roma. Sin embargo, a diferencia de los anteriores ejemplos, casi satura el pequeño claustro en que se encuentra - Bruschi (1987, p. 214) destaca el proyecto original que ubicaba el templete dentro de un patio mayor, también circular -. El lugar donde se ubica este templete, es la colina del Gianicolo, sitio donde la leyenda supone que fue crucificado San Pedro. El edificio de planta circular se encuentra ubicado sobre una plataforma escalonada o crepidoma seguido de un podio donde se eleva la columnata de orden toscano. El recinto que se halla en el interior de esta columnata posee tres puertas y un altar, situados en los extremos de dos ejes que se cruzan perpendicularmente. A su vez cada paño de muro situado entre dos puertas está decorado mediante un sistema organizado por pequeñas ventanas verticales flanqueadas por dos nichos. Para Summerson (1996, p. 52) cada columna tiene su correspondiente pilastra en el muro del edificio interior, aunque Bruschi (1987, p. 222) discrepa afirmando que el pequeño tamaño del edificio obligó a Bramante a hacer algunas correcciones sintácticas. El cuerpo central del templete adopta por encima de la balaustrada un aspecto de tambor con cuatro ventanas abiertas, cuatro ciegas y ocho nichos con conchas de gallones, terminando en cúpula de media naranja, linterna ciega y cruz. Las ventanas no tienen como objetivo brindar una articulación entre el exterior y el interior, sino proporcionar la luz necesaria para la iluminación natural y, fundamentalmente, contribuir a la explicitación de un orden geométrico y compositivo. Nada en el templete hace referencia a la colina, rodeada de extensos jardines, donde está situado.

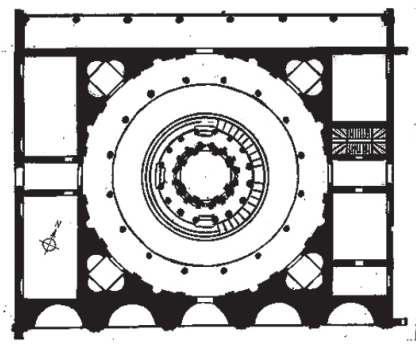

Figura 12. Iglesia de San Pedro en Montorio, Roma, planta.

Fuente: Reproducción de Roberto Céspedes.

La Iglesia de Il Redentore de Andrea Palladio se encuentra ubicada en un lugar privilegiado de Venecia, la isla de la Giudecca. Andrea Palladio dice:

... los sitios para los templos en la parte más noble y más celebre de la ciudad, lejos de los lugares deshonestos y en plazas bellas y adornadas en las cuales desemboquen muchas calles, donde cada parte del templo pueda ser vista con su dignidad y cauce devoción y maraville a quien quiera que lo vea y contemple ... (Palladio, 1570, p. 5) 
Una plataforma, apenas elevada sobre las aguas del canal, actúa como plazoleta, la que permite una perspectiva adecuada de la fachada. No existe en Il Redentore un atrio o espacio de transición entre el adentro y el afuera; el acceso es abrupto, con la única transición del espesor de los muros. El aventanamiento, a excepción de la zona del altar, se encuentra a gran altura por encima de la cornisa, adoptando la forma de ventanas termales, las que permiten dar luz a la blanca nave central con una iluminación difusa y casi lunar.

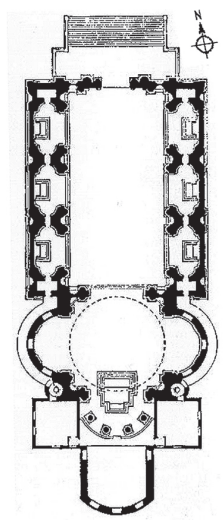

Figura 13. Iglesia de Il Redentore, Venecia, planta.

Fuente: Reproducción de Roberto Céspedes.

Sant'Ivo de Borromini fue diseñada para ser la capilla de la Universidad de la Sapienza en Roma. Por este motivo Francesco Borromini debió adaptar su diseño a los edificios ya existentes, articulando entonces la fachada de la iglesia con el patio del palacio de la Universidad. Es interesante destacar en esta obra el juego entre lo recto y lo curvo, lo cóncavo y lo convexo que se manifiesta en, por ejemplo, el contraste entre el interior, fruto de la intersección de dos triángulos y un círculo - que generan un hexágono y también una estrella - y un frente cóncavo constituido por dos plantas de cinco aberturas cada una, siendo la del medio el acceso al templo. A cada lado del nicho de la entrada hay dos salas hexagonales que configuran un espacio de transición entre el interior y el exterior, de tal modo que sólo una de las ventanas de la fachada - la ubicada por encima de la puerta central - da al recinto de la iglesia. Semejante solución se adopta con la fachada trasera: ninguna de sus ventanas da al espacio central. Por consiguiente, serán las aberturas ubicadas en la cúpula las que proporcionen luz natural a la iglesia, logrando el efecto de que todas las miradas se dirijan hacia arriba. 


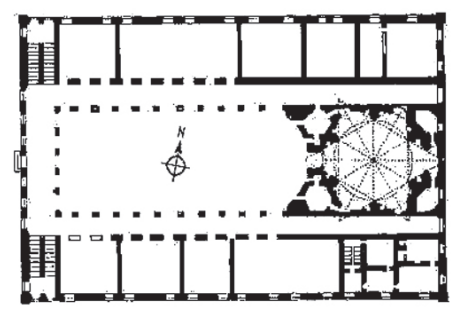

Figura 14. Capilla Sant'Ivo alla Sapienza, Roma, planta.

Fuente: Reproducción de Roberto Céspedes.

\section{Funcionalidad y circulaciones}

A partir del Renacimiento aparecerá una confrontación entre una concepción artística que propone un espacio centralizado - tomando como ideal geométrico la figura perfecta del círculo - y una operatividad litúrgica que prefiere las plantas longitudinales con circulaciones y accesos diferenciados, en un momento que, por su propia conflictividad - Reforma y Contrarreforma - cargará de ideología este debate de ningún modo trivial.

Pero, si la planta central era ideológicamente deseable, en la práctica se adaptaba mal a los servicios religiosos y a las costumbres que se habían desarrollado a lo largo del tiempo en iglesias basilicales. Los eclesiásticos que habían rechazado las propuestas de Alberti, Bramante y otros, no lo hacían simplemente para mantener las formas medievales, sino preveían los problemas que iba a plantear la celebración de ceremonias religiosas en un espacio central con el altar situado en el medio. Los arquitectos continuaron proponiendo plantas centrales. "En ningún otro dominio se puso tan de manifiesto este conflicto, entre las exigencias de los clientes y los ideales del artista, como en el de la arquitectura." (Gombrich, 1987, p. 239) Sin embargo, luego del Concilio de Trento algunos teólogos comenzaron a intervenir en la formulación de los programas de las iglesias. El más eficaz fue el cardenal Carlo Borromeo, cuyas 'Instructiones Fabricae et Supellectilis Ecclesiasticae’ favorecían explícitamente las plantas de cruz latina.

Destaca Zevi (1980, p. 84) en relación con la búsqueda de un riguroso orden geométrico que “... a la luz de esta exigencia intelectual es natural que los arquitectos del siglo XV examinaran todos los esquemas distributivos tradicionales .... Para ello recurrirían tanto al estudio de tipos como a la tratadística. El texto más conocido hasta ese momento era el de Vitruvio. Marcus Vitruvius Pollion redactó un extenso sumario de toda la teoría sobre la construcción que había sido escrita hasta ese momento en una obra titulada Los diez libros de la arquitectura - De architectura libri decem -. El libro de Vitruvio no pretendía ser un compendio de los conocimientos constructivos de su época sino, más bien, una teoría normativa: sus reglas están habitualmente basadas en puntos prácticos o en razonamientos; mientras que otras veces surgen de las costumbres o de la tradición histórica.

Además, Vitruvio presenta una clasificación del conjunto de requisitos para realizar una obra de arquitectura, que más tarde fue conocida como Trilogía Vitruviana: durabilidad - firmitas -; utilidad o 'conveniencia' - utilitas -; belleza - venustas -. Esta trilogía quedó como un modelo para casi todos los estudios posteriores de arquitectura y, luego, para la enseñanza formal de 
la disciplina: por un lado, aspectos constructivos; por el otro, los funcionales; por último, los estéticos o formales. Menos célebres son los seis componentes que Vitruvio define: ordenación - para Auguste Choisy concierne a la composición de un edificio, para Charles Perrault a las proporciones de la obra; las distintas traducciones y ediciones difieren en el sentido que se le dan a los términos utilizados -; disposición - ubicación de cada parte en relación con el todo -; euritmia - armonía del conjunto -; simetría; decoro - conveniencia -; distribución - comodidad -. De esta enumeración se desprende que la cuestión funcional, como se denomina actualmente, era considerada un tema menor, supeditada a cuestiones compositivas.

Empero, como se mencionó arriba, los arquitectos renacentistas estudiarán las diversas tipologías que asume el espacio religioso. Afirma entonces Argan (1981, p. 32) “... un edificio circular es un edificio de carácter puramente sagrado o dedicado al culto, y un edificio longitudinal es un edificio con funciones de congregación, de reunión de la comunidad para la enseñanza religiosa ...”. Sin embargo, en el Renacimiento se intentará asociar estos dos tipos de edificios.

La Capilla Pazzi posee una planta rectangular, transversal al eje que une el acceso con el altar, el que se encuentra, a su vez, en un ábside también rectangular. La forma de esta pequeña iglesia presenta una situación inversa a de las tradicionales basílicas longitudinales. No obstante, considerando que la misma era una capilla funeraria privada nada puede objetarse, pues, es posible que el número de fieles que concurrieran a orar fuera escaso.

La Iglesia de Sant'Andrea de Mantua fue construida en el lugar donde había existido un viejo monasterio benedictino con el objeto de recibir a la enorme cantidad de peregrinos que veneraban la reliquia de la 'Preciosísima Sangre de Cristo', de allí el tamaño monumental del templo. En esta obra, Alberti “... abandonó el tipo de iglesia basilical de nave y alas que había empleado Brunelleschi, y volvió a la forma de cruz latina con una nave de techo en bóveda de cañón.” (Murray, 1974, p. 36) Para De Fusco (1999, p. 196), esta propuesta tenía como objetivo evitar toda referencia a las iglesias de la Edad Media. La nave central tiene a cada lado, en lugar de naves laterales, una serie de capillas alternativamente abiertas y cerradas. El altar principal se ubica, como sucede tradicionalmente, en el ábside. Norberg Schulz (1980, p. 240) sostiene que la propuesta original contemplaba accesos similares al nartex principal para cada uno de los cruceros - o, mejor dicho, transepto -. La escala y el tamaño del edificio permite la congregación de gran cantidad de personas en la nave central participando de la ceremonia litúrgica, así como la oración de grupos más reducidos ante las capillas laterales, las que se encuentran delimitadas por tres escalones y un balaustre. Del mismo modo, el crucero ubicado bajo la cúpula central se encuentra demarcado por un pequeño podio y una balaustrada. Para Grayson (1988, p. 28), “... la innovación del espacio interior no es menos extraordinaria ... “que la integración de la planta basilical con el arco de triunfo.

San Pedro in Montorio es un edificio conmemorativo del martirio - un martirium o memoria - que sufriera apóstol en Roma. Bramante, según explica Argan (1981, p. 37), pretende materializar el arquetipo ejemplar de edificio de planta central, tomando para ello, por un lado, la tipología de Vitruvio y, por el otro, un edificio histórico como el templete de la Sibila en Tívoli. El edificio consta de dos recintos: por una parte, la cripta circular que cubre la roca del martirio del San Pedro; por la otra, la capilla superior con cuatro nichos con las imágenes de los evangelistas y un altar con una escultura del apóstol. Desde el pequeño podio que rodea al templo, se puede circular por el espacio entre la columnata y la cella o descender hacia la cripta 
por las escaleras excavadas en el terreno. Las ceremonias de culto que se realizan en el templete implican, por el tamaño del mismo y por su carácter conmemorativo, la concurrencia de unas pocas personas.

La iglesia de Il Redentor fue construida por orden del senado de Venecia y destinada a los Padres Capuchinos, quienes propusieron la organización de la planta según el modelo Franciscano. Es decir, enfatizando el carácter austero de la arquitectura y evitando los materiales ostentosos, en un todo de acuerdo con el voto de pobreza de los capuchinos y franciscanos, coincidente, además, con el espíritu del Concilio de Trento que impulsaba el regreso a la vida espiritual y el desapego de los bienes materiales. La crisis de la Reforma que llevó reexaminar a la iglesia como institución, al mismo tiempo, replanteó las formas de la iglesia como edificio: uno de los puntos que se discutía, además de la conveniencia de las plantas longitudinales, era la necesidad de mejorar la acústica y la visión del altar mediante la construcción de una única nave central y la utilización de cubiertas de madera a dos aguas en lugar de bóvedas. Esa misma incertidumbre afectó al proyecto inicial de Palladio para Il Redentore. Se le pidió entonces al arquitecto que presentara dos maquetas, una de forma redonda y otra rectangular. Aunque en principio pareciera que se inclinó por la primera de estas opciones, terminó adoptando la segunda. (Ackerman, 1987)

Las normas dictadas imponían resolver en una sola iglesia tres funciones eclesiásticas: la monástica o conventual, la votiva y la procesional. (Wundram, 2009. p. 82; Ackerman, 1987, p. 100; Wundram-Pape, 1990; Jung, 2007, p. 161) En cuanto a la función votiva, debe recordarse que 1575 se desató en Venecia una terrible epidemia que provocó unas 50.000 muertes. Cuando todo parecía perdido el Senado decidió solicitar la intervención divina formulando el voto de realizar una nueva iglesia consagrada al Redentor. Posteriormente se festejó el fin de la peste con una procesión de barcazas que llegaban hasta el templo, iniciando una tradición que continúa hasta el día de hoy.

Palladio encontró el modo de combinar tanto una ancha nave capaz de acoger a una gran congregación como unas capillas laterales lo bastante amplias para la celebración de los sacramentos, con el majestuoso espacio central cupulado. Las capillas laterales, separadas de la nave central por una balaustrada, están unidas por pasadizos abiertos, lo cual implica la fusión de dos soluciones tradicionales: las clásicas naves laterales y las capillas anexas. El transepto no sobresale de la nave, fundiéndose con el crucero en un único espacio donde se ubica el presbiterio y el altar sobreelevado. Aunque la disposición general de la iglesia es lineal, privilegiándose la participación de fieles en la nave central, la resolución final es de un espacio unitario, lo cual cumple con las directivas de la Contrarreforma de otorgar mejor visibilidad a las ceremonias litúrgicas. Sin embargo, el altar está claramente separado tanto del coro por una pantalla de columnas como de la nave central por una cancela y un par de pilares que estrechan el arco.

Para Argan, la obra de arte del Barroco era entendida como un medio destinado a impresionar, ejerciendo un importante efecto sobre los hombres, ilustrándolos, cautivándolos y convenciéndolos. El diseño de interior entonces adquiere efectos escenográficos, sorprendentes. La forma centralizada de la iglesia de Sant'Ivo, responde, como ya se dijo, al cruce de seis ejes, dos triángulos y un círculo, de tal modo que la centralidad no es la figura simple de San Pedro en Montorio, sino el resultado de curvas y rectas. En esta tensión, el altar se encuentra en un ábside ubicado sobre el eje principal del acceso, avanzando quien preside la ceremonia religiosa sobre el espacio central. Blunt (1987, p. 122) sostiene que estas distribuciones actúan 
... como escenarios idóneos para la contemplación del Sacramento. Pero en Sant'Ivo a ello se añade una nueva significación al tratarse de la disposición adecuada para la predicación y escucha de sermones, a los que la Universidad, dominada por la Facultad de Teología, concede gran importancia ...

A diferencia de las plantas claramente longitudinales donde la circulación es determinante y lineal o, las centrales donde el recorrido es desde la periferia al centro, en Sant'Ivo la complejidad y la ambigüedad de las formas proponen una circulación más abierta e indefinida. Los pequeños salones laterales se encuentran cerrados, aunque sus puertas son expresamente visibles y su función es difusa, actuando tal vez como sacristías, oficinas o depósitos. Los nichos se encuentran vacíos y no distraen a los fieles de la atención destinada al altar.

\section{Morfología, dimensión y escala}

No es posible dejar de señalar ciertas cuestiones como la idea de orden, inteligible a través de la propia morfología y explicitada claramente en innumerables tratados que se hará presente en el Renacimiento, se pondrá en crisis en el Manierismo y se tensionará y distorsionara en el Barroco. La noción de orden propuesta por el Renacimiento responderá así más a la expresión de un ideal racional que a una organización funcional. Ejemplos de ello se pueden observar en la Capilla Pazzi donde el eje circulatorio es perpendicular al lado mayor de la planta rectangular y no coincidente con él como ocurre en las basílicas tradicionales -, en Sant'Andrea de Mantua donde las naves laterales son reemplazadas por capillas alternativamente abiertas y cerradas, y en el templete de San Pedro en Montorio donde la planta es rotundamente circular. Sostiene en este sentido Gombrich (1987, p. 186) que las grises pilastras de la Capilla Pazzi comunican un orden clásico, no desempeñando ninguna verdadera función en la estructura del edificio: "Bruneleschi sólo las puso allí para destacar la forma y proporciones del interior."

Con relación a las formas que adoptarán los edificios de culto en este extenso período, es clara la inspiración en los modelos greco-romanos, sobre los que operará la creatividad y genio de cada artista. Summerson (1996, p. 10) define al edificio clásico como “.... aquel cuyos elementos decorativos proceden directa o indirectamente del vocabulario arquitectónico del mundo antiguo ...", aunque también considera 'clásica' a toda aquella arquitectura cuyo objetivo es el logro de una "... armonía demostrable entre sus partes ...."

Durante el medioevo el tamaño de los edificios de culto había sido motivo de una competencia entre diversas comunidades, pues, la altura, de algún modo, testimoniaba la devoción religiosa de un pueblo, mientras que en el Renacimiento, el carácter, la calidad y no sólo la dimensión de los edificios, evidenciaban una cualidad más profana: el poderío político y económico de una población y de sus dirigentes. Por ello, es que, si bien es frecuente en la arquitectura religiosa de este período la dimensión monumental - y como muestra sólo es necesario mencionar las cúpulas de dos iglesias como la Basílica de San Pedro y Santa María del Fiori -, también existen pequeñas obras como el Templete de San Pedro en Montorio y capillas privadas como la encargada por la familia Pazzi. Para Alberti entonces lo monumental no es lo determinante de una obra puesto que para él

... la belleza es una cierta conveniencia razonable (concinnitas) conservada en todas partes para el efecto a que se les quiere aplicar, si bien que no se las sabría 
agregar, disminuir o recambiar, sin hacer una pasmosa injusticia a la obra ... (Borissavlievitch, 1949, p. 76)

Asimismo, la escala de la arquitectura renacentista será la humana, puesto que a la manera de Protágoras 'el hombre es la medida de todas las cosas'. El símbolo de ello será el grabado de Leonardo con el hombre tipo encerrado en un círculo, donde cada parte - al igual que en la arquitectura y en el cosmos - guarda una proporción con las otras. Hay que recordar lo que el mismo Vitruvio decía:

... el centro natural del cuerpo humano es el ombligo; pues tendido el hombre supinamente, y abiertos brazos y piernas, si se pone un pie de compás en el ombligo, y se forma un círculo con el otro, tocará los extremos de los pies y manos. Lo mismo que en un círculo sucederá en un cuadrado; porque si se mide desde las plantas hasta la coronilla y se pasa la medida transversalmente a los brazos tendido, se hallara ser la altura igual a la anchura, resultando un cuadrado perfecto ... (Vitruvio, 1787 p. 59)

Afirma al respecto Norberg Schulz (1980, p. 223):

Es evidente que el hombre del Renacimiento creía en un cosmos ordenado, exactamente lo mismo que sus predecesores medievales pero su interpretación del concepto de orden era básicamente diferente. No creía lograr la seguridad existencial ocupando su puesto en el reino de Dios, sino que imaginaba el cosmos en términos numéricos y consideraba la arquitectura como una ciencia matemática cuyo objetivo era hacer visible el orden cósmico.

En su libro Mysterium Cosmographicum, Johannes Kepler creyó demostrar que el movimiento de los planetas cumplía las leyes pitagóricas de la armonía, considerando entonces que las distancias de los planetas al Sol venían dadas por esferas en el interior de poliedros perfectos, articuladas sucesivamente unas en el interior de otras.

Por otra parte, en relación con la evolución morfológica de este período es clara la transformación de los volúmenes simples - prismas, cilindros, semiesferas -, geométricos y arquetípicos del Renacimiento empleados en la Capilla Pazzi y en San Pedro in Montorio en formas de mayor complejidad como la de Il Redentore o Sant'Ivo. Del mismo modo, los ritmos simples y regulares de Brunelleschi y Bramante son reemplazados por proporciones más complejas a partir de Sant'Andrea de Alberti.

Afirma Bruno Zevi (1980 p. 95)

... el dinamismo barroco sigue toda la experiencia plástica y volumétrica del siglo XVI; rechaza sus ideales, pero no sus instrumentos. [...] pero en el barroco todo el muro se alabea, se pliega para crear un nuevo espacio. El movimiento barroco no es una simple conquista espacial, sino que constituye una categórica 
afirmación espacial de todo lo que representa espacio, volumetría y elementos decorativos en acción...

Coincide con estas observaciones Giulio Argan (1981, p. 114-115) quien señala que Borromini en Sant'Ivo logra mediante la continuidad indefinida en el espacio de las diferentes superficies “... la eliminación de la distinción tipológica entre el vano de la iglesia, el tambor, la cúpula y la linterna ..."

\section{Materiales, revestimientos, ornamentación, equipamiento y mobiliario}

Scott sostiene que (1970, p. 99) “.... en la arquitectura del Renacimiento el muro adquiere categoría propia y expresa sus propiedades ideales por medio de la decoración ...”

En el pórtico de la entrada de la Capilla Pazzi se combinan dos bóvedas de cañón casetonadas muy ornamentadas con una cúpula coloreada, obra de Luca della Robbia. En el interior, más sobrio - a tono con el carácter funerario del edificio -, las pilastras ornamentales, las cornisas y demás molduras que remarcan los arcos, bóvedas y la cúpula central, están realzadas en piedra serena gris que contrasta con la superficie blanca de los muros estucados que "... parece irradiar luz desde el interior ...” (Fanelli, 1977, p. 54), y la policromía de la cerámica vidriada - tondos -, también de della Robbia, presente en frisos y pechinas. Asimismo, la breve cuadrícula del piso de mármol pretende solamente expresar las proporciones matemáticas de su composición. (Gartner, 1998, p. 73) Prácticamente, es nulo el mobiliario - a excepción de un zócalo o banquina que despega el muro del piso - permitiendo así la percepción de la geométrica espacialidad y de las obras de arte aquí presentes.

En el interior de Sant'Andrea de Mantua, se hace evidente el 'horror vacui' del Barroco, puesto que la decoración fue añadida en pleno siglo XVIII, al igual que la elevada cúpula "... agregada por Juvarra después de 1732." (Norberg Schulz, 1980, p. 240) No obstante, vale recordar que el propio Alberti (1991, p. 246; SOLANA, 1994) en su libro De Re Aedificatoria justificaba la ornamentación en el interior de los templos, considerando que la misma era 'infinita' y que era una contribución a la belleza del edificio. Las bóvedas están formadas por casetones policromos, abundan los frescos en cúpulas, pechinas y arcos, mientras que en los muros las pinturas aparecen enmarcadas. Los gigantescos pilares que configuran un orden monumental presentan bajorrelieves ascendentes sobre un fondo coloreado, liberándose de la resolución tradicional de las columnas clásicas; el damero del piso colocado a $45^{\circ}$ con respecto a los muros y cortado por líneas transversales que remarcan el ritmo de las capillas abiertas y cerradas ya no enfatiza la visión en perspectiva, dando todo ello al conjunto un aspecto un tanto confuso. Wittkower $(1979$, p. 41) aclara que “... la pilastra es la transformación lógica de la columna para servir a la decoración de la pared. Cabe definirla como una columna achatada que ha perdido su valor dimensional y táctil ...”, coincidiendo con ello Scott (1970, p. 88) señala que los arquitectos renacentistas "Se apropiaron las formas de una construcción científica para usos puramente decorativos ...." Los escasos muebles se corresponden a las capillas laterales y son reclinatorios, atriles, ambones, mesas de altar, credencias y estandartes. Cada una de ellas posee retablos diferentes en formas y tamaños. No todas las capillas poseen púlpitos. Las sillas plegables presentes hoy en esta iglesia son una concesión al confort contemporáneo.

Las columnas exteriores del templete de San Pedro son de orden toscano. Los fustes de granito 
de las columnas fueron reutilizados de un templo antiguo, añadiéndoles una base y un capitel de mármol. Benévolo (1981, p. 369) destaca que “... existe una marcada diferencia en la precisión ejecutiva; los triglifos de las cornisas no corresponden exactamente con el eje de los capiteles, ni los casetones de cobertura del pórtico corresponden siempre a los triglifos ..., suponiendo que tal vez trabajaron dos grupos distintos de obreros. La planta circular de la capilla está dominada por cuatro ejes radiales. Dos de ellos enfrentan, por un lado, la puerta principal y el altar, por el otro, las dos puertas secundarias, mientras que los dos ejes restantes ordenan la ubicación de cuatro nichos con esculturas de los evangelistas. Sobre el altar, que posee un bajorrelieve con imágenes del martirio, se encuentra una estatua de San Pedro. Cubriendo la capilla se encuentra una cúpula gallonada que remata en una linterna con los cuatro escudos de España. En el nivel inferior se halla la cripta, decorada con estucos de mediados del siglo XVII con doce escenas de la vida del apóstol recogidas de los Evangelios. El solado de la cripta también manifiesta la presencia de los cuatro ejes principales u ocho radios que se articulan mediante un anillo central. Al igual que la capilla Pazzi, su función es más contemplativa que litúrgica, de tal modo que no existe mobiliario que destacar.

La superficie plana de la fachada de Il Redentore está trabajada para lograr más profundidad como un bajorrelieve combinando las figuras y columnas dentro del grosor del muro de piedra blanca de Istria que contrasta con la superficie ladrillera de las paredes laterales. En el interior, los muros, semicolumnas, pilastras y entablamentos, son de ladrillo estucado, pintados también de color blanco, logrando mediante este recurso controlar la luz reflejada, evitar el típico ennegrecimiento de la piedra, así como mantener la homogeneidad de los espacios interiores, mientras que los capiteles corintios y las cornisas están realizados en piedra gris, diferenciando el muro, de esta manera, de la bóveda y de la cúpula. Todo lo que no es manifiestamente arquitectura se lo ubica aparte en nichos y paneles destacándolos como objetos añadidos, de tal modo que ni las esculturas ni los ornamentos invaden las blancas superficies de las paredes, bóvedas o cúpulas, actuando los configurantes de la iglesia como un fondo neutro, para que, por contraste, estas imágenes y bajorrelieves se destaquen. Norberg Schulz (1980, p. 283) ensaya al respecto una hipótesis acerca de la profunda influencia que Palladio tuvo sobre la arquitectura protestante - que prescindió de las imágenes añadidas - considerando que no se adhirió a la retórica de la Contrarreforma, reemplazándola por una ambigüedad manierista. La aparente simpleza de las formas de Il Redentore contrasta con la elaborada composición del piso del transepto de Il Redentore que intenta recuperar el valor del espacio central impugnado desde el concilio de Trento.

Al no tener Il Redentore un nartex definido, en el acceso se ubica un pórtico o esonártex. A ambos lados de la entrada se encuentran sendas pilas de agua bendita. A lo largo de la nave central, como corresponde a un templo de planta longitudinal se encuentran dos hileras de bancos. Los confesionarios se apoyan en el tramo de muro ciego que divide la nave central de las capillas laterales. El altar, como se dijo antes, se encuentra encima de un podio. Detrás de él se ubica un sobrio retablo que se asemeja a un pequeño edificio, con dos grandes esculturas a cada lado y cinco imágenes menores en la parte superior, compuesto por diez columnas salomónicas apoyadas sobre el basamento, por encima de ellas un balaustre, culminando con una gran cúpula sobre la cual se encuentra una enorme cruz de madera.

Linazasoro (1981) destaca una diferencia entre el Renacimiento y el Barroco que no puede ser contemplada de manera puramente 'estilística': la oposición de los conceptos de 'identidad disciplinar' frente al de 'unidad del arte'. Mientras que la primera de estas nociones considera 
que cada disciplina artística tiene valor por si misma, intentando definir de manera precisa y canónica a las diferentes ramas del arte y lo específico de cada una; la segunda concepción busca una síntesis totalizante de todas las artes y descree de la autonomía disciplinar. Una muestra de la obra de arte específica o 'clásica' es la pintura de caballete del Renacimiento, un ejemplo de la idea de arte total es el Barroco, donde la pintura dependía de la escultura y la arquitectura de las demás artes. Concordante con este pensamiento, Hegel afirmaba en su Estética “... la arquitectura no puede ser autónoma, es un envoltorio de las demás artes .... No es casual que en este período la ópera llegara a su plenitud pues sintetizaba a la música con las artes plásticas. Esta consideración permite comprender la transformación de las pinturas, esculturas y bajorrelieves presentes en los muros de los espacios de culto del siglo XV, XVI y XVII. Por ende, en la iglesia de Sant'Ivo, ornamento y arquitectura no pueden ser cosas distintas.

Si se compara la capilla Pazzi con Sant'Ivo, se puede comprender la evolución de un recinto platónico y perfecto, receptor de obras de arte, a la configuración de una espacialidad en la que la compenetración de formas - cóncavas y convexas, rectas y curvas - determina un proceso de continua transformación de los elementos constructivos - muros, pilastras, cúpulas -, siendo entonces que toda la capilla es una obra de arte a ser contemplada. El tratamiento superficial de los muros y de la cúpula es de gran importancia para la percepción del movimiento. Las pilastras acusan los ángulos de las formas geométricas que da origen a la planta, a la vez que permiten apreciar la continuidad dinámica de las líneas que configuran el volumen desde la base de las pilastras hasta la linterna. Los nichos presentes en el muro dan cuenta del carácter volumétrico del mismo. La decoración de Sant'Ivo, utilizada para referirse a la continuidaddiscontinuidad de muro-techo, combina motivos orgánicos y claramente figurativos - cabezas aladas de querubines - con otros más abstractos o geométricos - estrellas -.

La principal obra de arte del interior es un altar de Pietro da Cortona, representando a Sant'Ivo, que aparece prácticamente como el único hecho cromático de la capilla, a excepción de las rejas doradas que se encuentran por encima de la balaustrada de la galería ubicada cerca de la zona del altar. Aunque se afirma (Blunt, 1987) que la intención original de Borromini fue colocar detrás del altar un semicírculo de columnas como en Il Redentore. El trazado del pavimento contribuye a la complejidad del edificio pues adopta una forma de octógono incluido dentro de una planta hexagonal. Las baldosas son figuras trapezoidales, unas blancas y otras grises, dispuestas en unidades radiales que salen del centro. Dado el carácter ambiguo de la planta, los bancos se ubican en forma de abanico. El altar posee a ambos lados credencias, sillas, relicarios, innumerables candeleros, $y$ un atril.

\section{Luz y color}

La iluminación en el Renacimiento pretende ser neutra, de tal manera que nada afecte a los colores naturales de las obras de arte presentes en ella. La luz es natural, no está mediatizada por ventanas coloreadas, siendo el vidrio, en general, transparente.

En la capilla Pazzi, se encuentran dos tipos de aventanamientos: por un lado, la linterna de la cúpula principal y las ventanas circulares que están ubicadas en el tambor de la misma solución similar a la que Brunelleschi también propuso para la Catedral de Florencia - que proporcionan iluminación cenital, homogénea durante las horas del día, y las cuatro ventanas del frente, cuya luz es atenuada por la presencia del pórtico de acceso. La excepción la constituye la raja y la pequeña ventana circular que se encuentran en el nicho del altar que mantienen la 
tradición gótica de los vitreaux, las que, junto a los candeleros, enfatizan el valor simbólico del lugar. En general, la capilla permanece en semipenumbra, siendo importante el contraste entre la luz del interior y el exterior, lo cual permite recrear el clima de capilla funeraria. Actualmente, se han agregado a la altura de las cornisas una serie de reflectores que iluminan los tondos pintados de della Robbia.

Señala Argan (1981, p. 108-109):

En la perfecta modular proporcionalidad del espacio (este es en efecto el primer ejemplo de aplicación integral, en toda la estructura, de la sección áurea, o sea de la relación por lo que una parte es a la otra lo que ésta es al todo) no pueden darse accidentes que detengan la difusión de la luz o de lugar a alternancias de sombras; esta luz, ya no es física sino espacial, es absoluta como el propio espacio.

Alberti como tratadista había estudiado la relación entre la iluminación y el color en sus libros Sobre la pintura - De Pictura - y Sobre la construcción - De re aedificatoria -, llegando a la conclusión que "El sentimiento de temor suscitado por la oscuridad contribuye por propia naturaleza a disponer la mente a la veneración en ese mismo modo en que la majestad se une en gran medida a la severidad." (Wittower, 1979 p. 16) Para alcanzar este objetivo, en Sant'Andrea, Alberti genera un contraste de luces y sombras. Para ello, recurre a la luz cenital proveniente de las ventanas horadadas en el tambor de la cúpula, las que proporcionan un carácter dramático al espacio central, así como a las altas ventanas circulares ubicadas en capillas laterales, en muros ciegos de la nave central, fachada principal, transepto y altar. Dado el tamaño del templo son innumerables los candeleros.

En San Pietro in Montorio, Bramante, recurre para iluminar la capilla a cuatro rajas ubicadas al nivel de planta baja, mientras que otras cuatro aberturas - ubicadas en los ejes de las puertas y el altar) proporcionan luz desde el tambor de la cúpula. Las mismas presentan pequeños motivos ornamentales que no llegan a colorear el ambiente interior.

En Il Redentore la luz no se reducía a iluminar. La diferente calidad de cada uno de los tres espacios principales - nave, transepto y coro - que se desarrollan en la planta, es también definida mediante la luz, diferenciándose de este modo: la nave alumbrada difusamente por las ventanas termales; el transepto iluminado de manera cenital y lateral; el coro iluminado de una luz brillante, contra el que se recortan las siluetas de las columnas en el hemiciclo. No obstante, la unidad de la iglesia quedaba salvaguardada por el uso casi exclusivo del blanco. Palladio afirmaba que "De todos los colores, ninguno conviene más a los templos que la blancura, puesto que la pureza del color y de la vida es sumamente grata a Dios ...". (Murray, 1974, p. 160) La naturaleza de la superficie reflectante de los blancos muros más la orientación de la planta de acuerdo al recorrido del sol, otorgará al interior de un ambiente humanizado diferenciándolo de los austeros efectos de los interiores góticos tardíos.

Si el color blanco de Il Redentore permitía el lucimiento de las imágenes y bajorrelieves por contraste entre lo arquitectónico y lo no arquitectónico, en Sant'Ivo el blanco confiere unidad a lo heterogéneo - molduras, ornamentos, imágenes, etc. -. En 1859, Sant'Ivo fue pintada imitando un marco policromo y resaltando algunos detalles con dorado a la hoja. Ya a fines del siglo XX fue restaurada volviendo a su color primitivo. (Wittkower, 1995) Blunt (1987) duda del uso del 
dorado en el original. La iluminación, a excepción de una única ventana ubicada sobre el acceso, enfrentada con el altar, proviene de la cúpula. En 1859, se modificó la iglesia colocándose arcos artesonados alrededor del altar y cegándose la ventana que daba a la fachada este. Como señala Norberg Schulz (1980, p. 282) con respecto a la arquitectura de la Contrarreforma: "La iluminación del interior no responde a la distribución homogénea de la luz propia del Renacimiento, y retorna al contraste paleocristiano entre una zona inferior relativamente oscura y las grandes ventanas del clerestorio ..." Este tipo de iluminación carga de dramatismo el ambiente, lo cual es parte de la evolución significativa del espacio homogéneo y geométrico del Renacimiento en una espacialidad fenoménica y no exclusivamente racional, puesto que la luz de Borromini tiene un carácter particular “... casi siempre rasante ...” (Argan, 1961, p 48) Hay que recordar que uno de los objetivos de la Contrarreforma es transformar el arte religioso en un instrumento de persuasión y propaganda recurriendo para ello a la experiencia emocional.

\section{Percepción sensorial}

La lógica funcional de la arquitectura gótica, donde cada parte es definida en relación con las restantes, es reemplazada por una lógica geométrica y abstracta durante el Renacimiento. Como resultado, surge una arquitectura claramente visual insertada en un espacio geométrico, homogéneo, perspectivo, (Panofsky, 1999) integralmente aprehendido por el sujeto que observa y cuyas relaciones proporcionales se muestran de forma analítica y objetiva, avaladas asimismo por innumerables tratados que certifican la validez de cada propuesta. Manfredo Tafuri sostiene entonces que (1978, p.12-13) "La racionalidad de la visión en perspectiva, investigada experimentalmente por Brunelleschi [...] fija una nueva construcción intelectual del espacio.” En el espacio renacentista, la intención es justamente contraria a la de la arquitectura gótica: el edificio no domina al individuo, sino que éste reflexiona sobre su espacialidad y su belleza. Se traslada el concepto de una arquitectura a la medida de Dios, a la de una a la medida del hombre. Se debe recordar lo que decía Argan (1981, p. 19):

La arquitectura de Composición es una arquitectura que se funda sobre la concepción objetiva del mundo y de la historia, de la naturaleza y de lo clásico; es por lo tanto una arquitectura que se plantea ella misma como concepción del mundo: es una arquitectura Weltanschauung.

Surge de la concepción de un espacio predefinido con leyes establecidas a partir de elementos extraídos de la antigüedad, o de la propia gramática constructiva. De este modo, la percepción del espacio, no tiene como finalidad el estimulo meramente sensible, sino más bien un goce estético e intelectual. Cada edificio del Renacimiento se situaría como un argumento más a favor de esta tesis de racionalidad y orden.

En la Capilla Pazzi, las columnas del pórtico, las pilastras, las cornisas, los ejes trazados en el solado, todos y cada uno de los elementos de la composición tienen como objetivo manifestar un orden geométrico, cuya comprensión intelectual es su finalidad.

En Sant'Andrea, Alberti quiere experimentar con la transformación de un tipo arquitectónico, el Arco de Triunfo, meramente conmemorativo y casi escultórico - cuyo origen se remonta a la antigüedad romana - hasta convertirlo en un nuevo tipo espacial. La monumentalidad de la escala, la articulación de las capillas laterales con la nave central, la profundidad de las bóvedas 
de cañón y su encuentro con la cúpula dan como resultado un producto claro y preciso, que puede ser utilizado como modelo para imitar. La consistencia de cada parte en función del todo es señalada por Mc Lean (2007, p. 112):

... [los] casetones pintados de la bóveda de cañón de la nave responden a los casetones de la bóveda de la fachada y tiene resonancia también en las capillas laterales, cada una de las cuales repite el motivo del arco de triunfo y de la bóveda de cañón de la fachada ...

Por otra parte, Bruschi (1987, p. 222) sostiene que el templete San Pedro in Montorio

... está pensado como representación en perspectiva sobre un cuadro. De aquí que se recurran a medidas típicamente pictóricas: el contraste y la graduación de la sombra, la búsqueda de efectos lumínicos y atmosféricos, a los que contribuyen la cualidad cromática, óptica y táctil de diferentes superficies. De aquí que se utilicen materiales diversos - travertino, granito, mármol, enlucidos y estucos - pero de una homogénea tonalidad clara para producir una especie de monotonía ...

La ausencia del claustro circular, originalmente pensado, en cuyo centro se ubicaría el temple, impide percibir este orden absoluto y cósmico.

Asimismo, Rudolf Wittkower (1979, p. 154) señala que en la Iglesia de Il Redentore de Palladio “... la nave y la zona centralizante de la cúpula - que son objetivamente entidades arquitectónicas totalmente distintas - forman una unidad óptica para el que las contempla desde la entrada ...,, a las que contribuye el carácter monocromático del templo.

Durante el Barroco hay un cambio en la sensibilidad: de lo puramente racional e intelectivo se pasa a un plano fenoménico y emocional. El arte y la arquitectura deben conmover y emocionar. Toman (2004, p. 7) destaca el carácter teatral de la arquitectura donde “... sus formas pretenden impresionar, convencer, provocar un movimiento interior ...” De tal modo, que el templo dedicado a la sabiduría - Sant'Ivo della Sapienza - es la obra que más profundamente apela a lo sorpresivo, emocional, que no puede ser entendida en términos puramente lógicos o geométricos. Su forma configurada por triángulos, círculos, hexágonos, octógonos, arcos cóncavos y convexos, sin embargo, configura un espacio a la vez ambiguo y unitario. Dice entonces Norberg Schulz (1979, p. 314) que Borromini “.... hizo del espacio mismo un accidente vivo, que expresa la posición siempre cambiante del hombre en el mundo ...”

\section{Simbología e iconografía}

Afirma Tafuri (1978, p. 115):

El profundo carácter ideológico del humanismo clasicista se expresa a través de dos postulados de fondo, implícitos en la arquitectura de Brunelleschi y con el tiempo convertidos en principios teóricos del pensamiento sobre el arte y de la especulación filosófica: la identidad de Naturaleza y Razón, por un lado, y el 
reconocimiento de la clasicidad como una segunda y más perfecta Naturaleza, por otro ...

En la capilla Pazzi aparecen diecisiete tondos de terracota esmaltada creados por Luca Della Robbia: cuatro en las pechinas - algunos como Argan (1981, p. 31) y Heydenreich (1991, p. 26) atribuyen a los tondos ubicados sobre las pechinas al propio Brunelleschi - que representan los evangelistas, uno en el exterior - San Andrés; hay que recordar que Andrea Pazzi encargó la capilla a Brunelleschi - y doce en el friso interior - apóstoles -. Los tondos son ligeramente cóncavos con el fondo en azul, a excepción de los ubicados en las pechinas que presentan más colorido. Otras figuras de carácter más alegórico aparecen en los frisos como peces y corderos - símbolos del Cristo -, y delfines, emblemas de la familia Pazzi, en las pechinas y en el centro de la cúpula exterior. Las dos únicas ventanas coloreadas, muestran una al Padre Eterno óculo - y otra, la rectangular, nuevamente a San Andrés, obras ambas de Alesso Baldovinetti. La pequeña cúpula dispuesta sobre el altar representa al cielo.

San Pedro in Montorio fue encargado por los Reyes Católicos, quienes retribuían la gracia divina que les había facilitado: para algunos autores, la expulsión de los moros de territorio español; para otros, el nacimiento del primogénito varón, el infante Don Juan. Es por eso que en el pórtico aparecen los blasones de los Reyes Católicos timbrados con corona real y el águila nimbada de San Juan y, en la linterna ciega, los cuatro escudos de España. Cada una de las partes tiene un significado: la cripta representa el martirio del apóstol y la primitiva iglesia de las catacumbas; el peristilo a la iglesia militante; la cúpula a la Iglesia triunfante; el crepidoma, compuesto por tres escalones, encarna las tres virtudes teologales - fe, esperanza y caridad -. Por otra parte, la concepción simbólica de Bramante se inscribe dentro de un pensamiento neoplatónico, ya que el círculo y la esfera eran considerados como figuras ideales y debían estar presentes en todas aquellas obras que buscasen la perfección estética.

En la Basílica de Sant'Andrea de Mantua, cada capilla constituye un orden iconográfico propio, debido substancialmente a que fueron diversos los artistas que trabajaron en ellas, durante varios siglos: Andrea Mantenga, Lorenzo Costa el viejo, Lorenzo Costa el joven, Antonio Allegri - il Correggio -, Arrivabene, Rinaldo Montavano, el Andreasino, incluso Giulio Romano. Los temas difieren desde la legenda de San Longino - El centurión que trajo la reliquia de la Sangre de Cristo - hasta la Inmaculada Concepción, pasado por San Juan el Bautista. En la cúpula, obra de Filippo Juvarra, cuatro estatuas alegóricas ubicadas en nichos representan las tres virtudes teologales: fe, esperanza, caridad, más una cuarta que simboliza la religión.

El Manierismo es una etapa de transición entre el Renacimiento - momento cumbre del fresco y la pintura de caballete - y el Barroco - cuando reina la obra de arte total -, caracterizado por la incertidumbre y el conflicto. Es también esta misma época donde se enfrenta la Reforma Protestante y la Contrarreforma Católica, siendo que algunos de los primeros como afirma Gombrich (1987, p. 366) impulsaban la eliminación de imágenes y la prohibición del culto a las mismas. Será tal vez por ello que en la Iglesia de Il Redentore, las obras pictóricas y escultóricas son escasas y se remiten a los altares. La luz y la perfecta blancura son considerados entonces elementos suficientes para la oración.

La iglesia de Sant'Ivo, como ya se dijo, combina la figura de dos triángulos - que representan a la Santísima Trinidad - con el círculo - que simboliza la perfección -. El resultado es la estrella 
de David y un hexágono - que significa la sabiduría -. Existe en todas las formas utilizadas en la ornamentación una directa alusión a los símbolos de los escudos de las poderosas familias Barberini - el triángulo formado por tres abejas y la celdilla hexagonal de los panales - Pamphili - cornas - y Chigi - montañas y estrellas -, a las que pertenecían los tres papas - Urbano VIII, Inocencio X, Alejandro VII - que reinaron durante la construcción del templo.

\section{Conclusiones}

De nuestro análisis precedente se puede extraer algunas conclusiones.

La arquitectura y el diseño de interiores mantuvieron como valor constante en este extenso período dos características principales. Por un lado, la recuperación del ideal clásico de belleza inspirado en la arquitectura de la antigüedad grecorromana, lo cual implicaba no sólo un repertorio estilístico, sino también una estructura sintáctica, ligada a la noción de orden. Entendido este último en un sentido amplio: desde la organización sistemática del Renacimiento pasando por la composición dinámica del Manierismo hasta la integración inclusiva y compleja del Barroco. Por otro lado, la percepción de la naturaleza como creación suprema de Dios y como elemento cuya perfección debe ser imitada y conocida. Esto sucede no sólo en el campo artístico sino en el científico, donde personajes como Bacon y Galileo se sumergen en 'libro de la naturaleza' para entender el plan de Dios.

Es además interesante notar que en este período de tiempo la concepción espacial oscila entre dos extremos opuestos pero semejantes. En un lado, un humanismo exacerbado que detiene su mirada en el ser humano dejando atrás el teocentrismo medieval. Este humanismo, confía en el poder del hombre, como individuo creado a imagen y semejanza de Dios, exalta su fuerza e inteligencia, siendo la obra de arte una demostración de su poderío. El círculo es el emblema de este momento: todos son iguales ante Dios; la perfección puede ser alcanzada. La perspectiva pretende señalar una visión objetiva y analítica de una realidad de puros valores matemáticos. En el otro extremo, un movimiento artístico, el barroco, que se presenta triunfante y seguro, esta vez sustentado ya no en el poder del hombre individual - el artista del Renacimiento sino en la tradición y en la autoridad - la Iglesia de Roma restaurada, una de las tendencias de la Reforma o el poder monárquico absoluto -. El óvalo es el símbolo del Barroco: no son todos iguales. La tensión y el conflicto se superan si se acepta esta condición. La fuerza ya no reside en el hombre sino en aquel hombre que tenga el poder. La perspectiva pone en evidencia que los puntos de vista son distintos. En el medio de estos períodos de seguridad y poderío, el momento angustiante del Manierismo. La conciencia de la ambigüedad, el conflicto y la duda. La pérdida de fe en el ser humano individual. La necesidad de trascendencia más allá del hombre mismo. La búsqueda de las certezas, aún a costa de la pérdida de libertad.

Por otra parte, hay un proceso de transformación en el tratamiento de los aspectos religiosos. Mientras que en el Renacimiento la temática era tratada de manera casi profana, es decir, desde un enfoque mesurado y racional, donde la composición geométrica - y pitagórica - determinaba el número de ventanas, imágenes y altares, en el Barroco hay un abordaje de las cuestiones litúrgicas y religiosas a partir de un compromiso emocional donde se jugaba la pervivencia de la 'verdadera' iglesia - tanto para los reformistas como para los de la contrarreforma -. La Iglesia, al igual que monarquías absolutas, percibe el valor que tiene el arte como medio de propaganda y control social. Es por ello que se emprende importantes obras, realizadas por los mejores ar- 
tistas, no sólo para embellecer las ciudades, dar gloria a Dios o manifestar el poder del mecenas de turno, sino para emocionar y seducir al hombre común. De una manera semejante a la de la época medieval, el arte barroco estaba destinado a entender, enseñar y conmover de inmediato. Para ello, recurría tanto a escenas costumbristas y conocidas como a alegorías y metáforas,e incluso, a situaciones espaciales monumentales y de tono dramático. La necesidad de una arquitectura y de un diseño de interior dirigido a un espectador, fue una regla común de la etapa del absolutismo ilustrado, pero también permitió que el sujeto adquiriera conciencia de su propio e importante papel, lo que devendría luego en la caída de este mismo régimen.

\section{Lista de Referencias Bibliográficas}

Alberti, L. B. (1991) De Re Aedificatoria. Madrid: Akal.

Argan, G. C. (1981) Brunelleschi. Madrid: Xarait Ediciones.

Bruschi, A. (1987) Bramante. Bilbao: Xarait Ediciones.

Gombrich, E. H. (1987) Historia del arte. Madrid: Alianza.

Heydenreich, L. (1991) Arquitectura en Italia 1400-1600. Madrid: Cátedra.

Palladio, A. (1570) Lib. IV, cap. 1, Del sitio que se debe elegir para edificar un templo. En Los cuatro libros de arquitectura. Venise: Dominico de'Franceschi. [consulta: junio de 2009]: <http:// architectura.cesr.univ-tours.fr/Traite/Images/LES1338Index.asp>

Sendra Salas, J. J.; Navarro Casas, J. (1996) El concilio de Trento y las condiciones acústicas en las iglesias en Actas del Primer Congreso Nacional de Historia de la Construcción, Madrid, 19-21 septiembre 1996. Madrid: Instituto Juan de Herrera.

Solana, G. (1994) "Alberti y su obra en Mantua" en Arquitectura Viva, № 38, septiembre/octubre, pp. 69-71

Vitruvio, M. V. P. (1787) Los Diez Libros De Arquitectura, traducción del Presb. Joseph Ortiz y Sanz. Madrid: Imprenta Real. [consulta: junio de 2009]: <http://www.artifexbalear.org/ vitrubio/0.jpg>

Wittkower, R. (1979) Los fundamentos de la arquitectura en la edad del humanismo. Madrid: Alianza. Wittkower, R. (1995) Arte y Arquitectura en Italia. Madrid: Cátedra.

\section{Bibliografía}

Ackerman, J. S. (1987) Palladio. Madrid: Xarait Ediciones.

Alberti, L. B. (1991) De Re Aedificatoria. Madrid: Akal.

Argan, G. C. (1961) Borromini. Buenos Aires: Nueva Visión.

Argan, G. C. (1981) Brunelleschi. Madrid: Xarait Ediciones.

A.A.V.V (1979) Leonis Baptiste Alberti en Architural Design Vol. 49, N 5-6.

Benevolo, L. (1981) Historia de la arquitectura del Renacimiento. 2 Tomos. Barcelona: Gustavo Gili. Blunt, A. (1987) Borromini. Madrid: Alianza Forma.

Borissavlievitch, M. (1949) Las teorías de la Arquitectura. Buenos Aires: El Ateneo.

Burke, P. (1993) El renacimiento italiano. Cultura y sociedad en Italia. Madrid: Alianza.

Bruschi, A. (1987) Bramante. Bilbao: Xarait Ediciones.

De Fusco, R. (1999) El Quatrocento en Italia. Madrid: Istmo.

Fanelli, G. (1977) Brunelleschi. Florencia: Scala Istituto Fotografico Editoriale. 
Gärtner, P. (1998) Filippo Brunelleschi 1377-1446. Colonia: Könemann.

Gombrich, E. H. (1990) Historia del arte. Madrid; Alianza.

Grayson, C. (1988) Leon Battista Alberti, Arquitecto en ROVIRA, J.; Muntada, A. (comp) (1988)

León Battista Alberti. Barcelona: Editorial Stylos.

Heydenreich, L. (1991) Arquitectura en Italia 1400-1600. Madrid: Cátedra.

Jung, W. (2007) La arquitectura del Alto Renacimiento y del Manierismo en Roma e Italia central en Toman, R. (ed) (2007) El arte en Italia del Renacimiento. Arquitectura, Escultura, Pintura, Dibujo. Barcelona: Tandem.

Mc LEAN, A. (2007) La arquitectura del Renacimiento Temprano en Florencia e Italia central en Toman, R. (ed) (2007) El arte en Italia del Renacimiento. Arquitectura, Escultura, Pintura, Dibujo. Barcelona: Tandem.

Murray, P. (1974) Arquitectura del Renacimiento. Madrid: Aguilar.

Nieto Alcaide, V. (1980) El Renacimiento. Formación y crisis del modelo clásico. Madrid: Istmo.

Nieto Alcaide, V. (1997) La luz, símbolo y sistema visual (el espacio y la luz en el arte gótica y del renacimiento). Madrid: Cátedra.

Norberg Schulz, C. (1980) El significado en la arquitectura occidental. En Summa, Buenos Aires, Vol 4: La arquitectura del Renacimiento. La arquitectura manierista.

Norberg Schulz, C. (1979) El Significado en la arquitectura occidental. En Summa, Buenos

Aires, Vol 5: La arquitectura barroca. El Iluminismo.

Norberg Schulz, C. (1982) Historia de la Arquitectura. Arquitectura Barroca. Buenos Aires: Viscontea.

Norberg Schulz, C. (1977) Arquitectura barroca. Madrid: Aguilar.

Palladio, A. (1570) Lib. IV, cap. 1, Del sitio que se debe elegir para edificar un templo. En Los cuatro libros de arquitectura. Venise: Dominico de'Franceschi. [consulta: junio de 2009]: $<$ http://architectura.cesr.univ-tours.fr/Traite/Images/LES1338Index.asp $>$

Panofsky, E. (1975) Renacimiento y renacimientos en el arte occidental. Madrid: Alianza.

Panofsky, E. (1972) Estudios de iconología. Madrid: Alianza.

Panofsky, E. (1999) La perspectiva como 'forma simbólica'. Barcelona: Editorial Tusquets.

Rovira, J.; Muntada, A. (comp) (1988) León Battista Alberti. Barcelona: Editorial Stylos.

Sendra Salas, J. J.; Navarro Casas, J. (1996) El concilio de Trento y las condiciones acústicas en las iglesias en Actas del Primer Congreso Nacional de Historia de la Construcción, Madrid, 19-21 septiembre 1996. Madrid: Instituto Juan de Herrera.

Solana, G. (1994) Alberti y su obra en Mantua en Arquitectura Viva, № 38, septiembre/octubre, pp. 69-71.

Summerson, J. (1996) El lenguaje clásico de la arquitectura. Barcelona: Editorial Gustavo Gili.

Tafuri, M. (1978) La arquitectura del Humanismo. Madrid: Xarait Editores.

Toman, R. (ed) (2004) El Barroco. Colonia: Köneman.

Toman, R. (ed) (2007) El arte en Italia del Renacimiento. Arquitectura, Escultura, Pintura, Dibujo. Barcelona: Tandem.

Vitruvio, M. V. P. (1787) Los Diez Libros De Arquitectura, traducción del Presb. Joseph Ortiz y Sanz. Madrid: Imprenta Real. [consulta: junio de 2009]: <http://www.artifexbalear.org/ vitrubio/0.jpg >

Wittkower, R. (1979) Los fundamentos de la arquitectura en la edad del humanismo. Madrid: Alianza. Wittkower, R. (1995) Arte y Arquitectura en Italia. Madrid: Cátedra. 
Wundram, M. (2009) Palladio, Colonia: Taschen.

Wundram, M.; Pape, T. (1990) Andrea Palladio, Colonia: Benedikt Taschen.

Zevi, B. (1980) Saber ver la arquitectura. Barcelona: Poseidón.

Summary: Interior design from Renaissance, Mannerism and Baroque, was distinguished for the use of Greco-roman stylish forms and for the employ of an ordered system of geometric proportions. That configured interior space was evolving from simplified and defined solutions to intricate and ambiguous ones.

Key words: Alberti - Baroque - Borromini - Bramante - Brunelleschi - Il redentore - Interior Design - Mannerism - Pazzi Chapel - Redeemer - Renaissance - San Pietro in Montorio - Sant'Andrea Mantua - Sant'Ivo.

Resumo: O design de interiores do Renascimento, Maneirismo e Barroco se caracterizou pela utilização tanto de formas estilísticas da antigüidade greco-romana quanto dum sistema ordenado de proporções geométricas. A espacialidade assim conformada foi evolucionando de propostas simplificadas e definidas a soluções de grande complexidade e ambigüidade.

Palavras chave: Alberti - Barroco - Borromini - Bramante - Brunelleschi - Capela Pazzi - Design de interiores - Il Redentore - Maneirismo - Palladio - Sant'Ivo - Renascimento - Sant'Andrea de Mântua - São Pedro em Montorio. 